\title{
An M-Learning Framework in the Podcast Form (MPF) using Context-Aware Technology
}

\author{
*Mohamed A.Amasha \\ Department of Computer Preparing Teacher \\ Dumyat University \\ Dumyat, Egypt
}

\author{
Elsaeed E. AbdElrazek \\ Department of Computer Preparing Teacher \\ Dumyat University \\ Dumyat, Egypt
}

\begin{abstract}
Mobile computing is rapidly transforming the world in which we live, with the advent of iPhones, iPads, tablet computers, and Android smartphones. M-learning in the podcast form (MPF) is a recent development forconveying coursecontent to students in higher education. Context-aware technologies use temporal and environmental information to determine context. Thisstudy presents a theoretical framework for using context awareness, M-learning in the podcast forminvestigate the effectiveness of using MPF engagement with context-aware technology in Teaching and Learning a multimedia course. The framework is based on two principal dimensions (MPF andcontext-aware technology), and it contributes to support researchers in e-learning and ubiquitous learning. The study was conducted onstudents $(n=42)$ enrolled ina multimedia course (IS 450) at QassimUniversity. After finishing the course, theycompleted an online survey to give their feedback on the effectiveness of using MPF with context-aware technology.The results indicate that learners had a positive attitude towards usingMPF with context awarenesstechnology, and that they considered it a great way to develop their knowledge and receive course information.This study demonstrates the ability of context-aware technology to enhance the behaviour of learners by using m-learning in the podcast form.
\end{abstract}

Keywords-M-Learning; Context Aware; E-Learning; RSS; Podcast

\section{INTRODUCTION}

Mobile learning (m-learning) isdefined as the use of smart phones in education and training, and it allows students to access educational content through mobile devices [9]. It alsopermits students to follow training activities, helps in publishing the communication content, and makes communication tools like discussion boards, forums, and social media available to the learner.M-learning has become the new version of E-learning [12].

U-learning is a combination of both M-learning and Elearning. It is a new model based on context-aware technology, and it allows autonomous learning at anytime and any place using mobile devices, radio frequency identification (RFID), and sensor technologies. M-learning depends on podcasting to disseminate educational content from the instructor to the students, who receive it through podcatchers on their computing devices (PADs, iPhone, android, laptop, and $\mathrm{pc}$ ). In order for the learnersto complete the learning process properly, the environment surrounding them (place, time, location, and status) should be defined. The following questions should be answered using this strategy: "Who is the learner? Where is the learner? When is he/she now? What is he/she doing? Why is he/she doing so? What are the surrounding environmental characteristics? Where is the learner's location? Context-aware technology can answer these questions.

MPFdescribes any information that characterizes a situation that involves the interaction between learners, content of the course, and the real world. Previous studies mainly focused on using podcasting as a teaching tool and its impact on the learning process, without any consideration of the status and surroundings of learners. This study will focus on these aspects, especially since there isinsufficient research on using MPF with context-aware technology in the field of elearning. Therefore, the current study presents a framework of using context-awaretechnology in M-learning in the podcast form (MPF) and scope to investigate the effectiveness of using MPF engagement with context-aware technology in teaching and learning multimedia courses. We hope this study can achieve an improvement in pedagogical effectiveness, and reveal the educational value in e-learning courses that depend on a podcast form.

\section{LITERATURE REVIEW}

M-learning is the second revolution of e-learning, arriving with the great spate of mobile devices and wireless technologies.To support and develop the learning experience, it uses mobile computing technologies that can be mixed together to involve and motivate learners anywhere, at any time[21].The employment of mobile devices such ascell phones, smartphones, netbooks, and tablet PCs enables learners to deliver e-content to their own locations, in any environment suitable for learning[14].Context awareness techniques help students have their academic content regardless of the time or place of the learner, and to relatetheir learning activities to the real world.[5][6]. "Context awareness technology" in M-learning is a situation in which the student is involvedin a reality, while using mobile devices to support his or her learning [7]. Radio-frequency identification (RFID) canalso be used to facilitate the context-aware mechanism andenhance ubiquitous and mobile learning [12][15].

Mobile computing is rapidly transforming the world in which we live, with the advent of iPhones, iPads, tablet computers, and Android smartphones[19] [16][13]. Nowadays, M-learning uses podcast technology, which appeared in 2004 with the emergence of the second generation of web (web 2.0), to transform content for the learners. A 
podcast is defined as an MP3 or MP4 media file that has been uploaded onto a website, and can thus be transmitted directly to the audience via their smart devices, or through social media, using RSS.

The appearance of podcasts has revolutionized the way of dealing with multimedia, and also introduced an innovative method for learning and teaching. Additionally,research has proven the efficiency of using iPod devices in transmitting content. Lately, the use of podcasts has widely increased, coinciding with the revolution and revaluation of smart devices.Transmitting educational content started with smartphones(instead of iPhones) using podcatchers, in a process known as m-learning or u-learning. Whatever the name used for this kind of learning, it is clear that communication between teacher and learner can now be facilitated through smart devices, with the content rendered into a podcast format.[1]

Using this method in the learning process has many advantages, such as:

- The flexibility in being able to listen to the content anywhere.

- The ability to listen to the content many times.

- Clarifying ambiguous points.

- It could be a substitution for going to campus.

- It can be used for exam revision.

However, as with anything else, this technology may have some shortcomings, such as the inability to identify the learner or make a link between the real world and the virtual world.Additionally, the teacher cannotidentify the special content for the individual learner (place - time - status.In this research, we strive to develop a framework for using devicesfor MPF, and to link it with the individual context for the learner.Moreover,in order to link the real and virtual environments, we will clarify how this kind of learning enables communication between learners and teachers in a virtual environment and recognizesthe individual context for each learner.

\section{THEORETICAL FRAMEWORK}

Thisstudy suggests a model to develop context-aware programs in M-Learning applications, which are provided in podcast form (MPF).We provide a framework that supports the application developer in the following key ways:

- It provides a communication method between the teacher and the learner, as well as dispensing the educational content through mobile devices.

- It provides a methodological framework for using context technology in MPF.

- It provides an interaction mechanism between the sensors devices, the objects, the learner, and the content provider.

- It provides an easy mechanism to use programming and programming tools in MPF design.

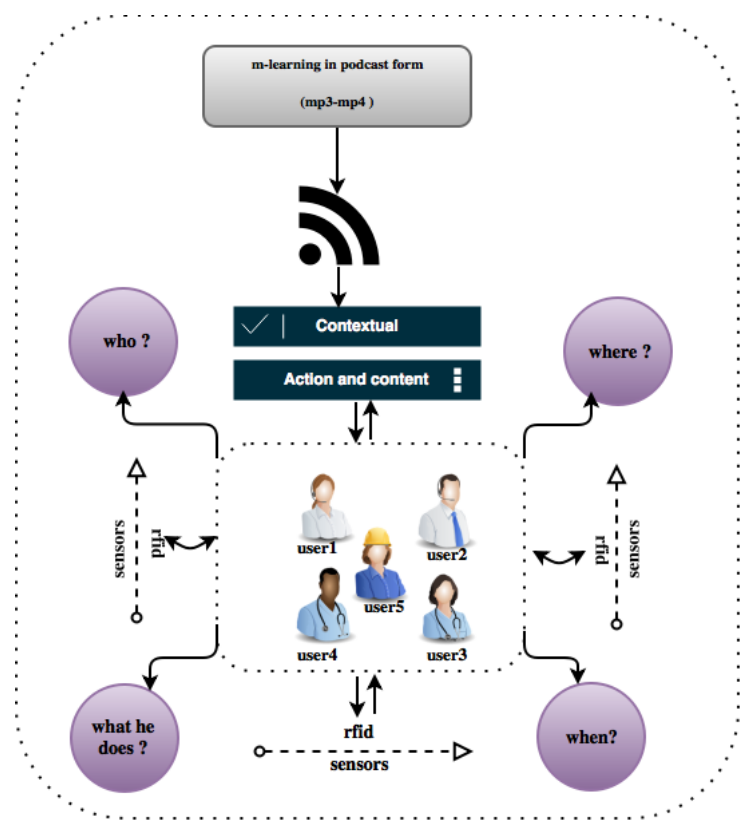

Fig. 1. Using context awareness in podcast form

In this section, we present anm-learning framework based on context-aware technology.It consists of two sections:mlearning in the podcast form and context-aware categories.

\section{A. M-learning in the podcast form (MPF)}

A podcast is an MP3 or MP4 (audio or video) file that is uploadedtoa webhosting server and thenautomatically broadcast to the users' devices, enabling the user to listen to file directly or download it to listenlater[10][3].The applicationsof educationalm-learning are based on broadcasting lessons to students' devices as a podcast. The following steps show how a podcast is created and delivered to the learners. [20]

\section{a) Record sound (MP3) and video (MP4)}

AnMP3 output file can be created using all types of soundrecording software. For the purposes of this study, a free, open-source program called Audacity was used for recording the educational content. Audacity is widely available for download from the internet, and it is compatible with most operating systems (OS). It needs to be installed and configured to capture the input at the right settings, since the wrong settings can produce a variety of negative results such as poor sound quality.

Using Audacity as an example, we will provide a walkthrough of software settings. First of all, we set Sample rate to $44,100 \mathrm{~Hz}$ and Sample format to a 32-bit float.Next, we need to adjust the settings for the format to which the filewill be exported, which should be the MP3 format. We should also pay attention to the bit rate for the exported file, which should be the same as the bit rate used for recording the original audio file.[17]

Similarly, tocreate an MP4file we can use any video capture software, such as SnagIt, which enablesthe user to create AVI (Audio Video Interleave) files. We first record the lesson, using print screen key, save it as AVI, and thenupload 
the file on www.archive.org(hosting). TheAVI file will be automatically converted to MP4 as it uploadsto the archive. We use the upload link on the archive homepage use the upload link to upload the file, copy the URL of the MP4 page that is created, and paste it on the desired web page or blog.

\section{b) Hosting podcast}

There are three methods to hosting the episodes on server. A private server can be set up using server software. A number of websites produce web server software, but one of the most popular is Apache, which can be found at www.apache.org. To connect the server to a network, an unchanging static Internet Protocol (IP) address is needed, to allow users to find the server online. TheSecond method is to share the server, and this can be done through creating an account on blogsites like Blogger or WordPress. These blog sites use a database, whichcan be usedfor uploading the podcast episode. The third and final method is by using host services, which are specialized services configured to host the episode. With these services, we only need to upload the file and update the podcast blog. Thepodcast will have a name that includes the service domain, like this one for our podcast on LibSyn: "fir.libsyn.com." If having a unique URL is important to podcasters, they can get a dedicated domain and redirect it to the actual location of the file.Host services like LibSyn(LiberatedSyndication) at http://www.libsyn.comand Switchpod at www.switchpod.comhost podcasts and provide RSS feed for each episodes.Since the second method is the easiest, we chose to use it in this study.

The next step is creating a web page or ablogto upload episodes from the hosting site, with a dedicated page named "podcast" that is linked to the MP3 or MP4files, and containing information on how to subscribe.A weblog or blog is a website created using template with html code linked to a database.In weblog setting, changing "Enable Title Links and Enclosure Links" from "No"to "Yes"allowsthe blog to provide subscriptionsto the hosted files. For each episode, a new postis created,the file URL is inputted into the "Enclosure Links,"and an RSS is obtained fromFeedBurneror the blog setting. From blog overview, "add a gadget" is selected and the RSS feed is inputted. The RSS feed is then shared with learners, who use it with dedicated RSS readers like iTunes.

\section{c) Reallysimple syndication (RSS)}

To distribute and publish podcast episodes, an RSS feed is needed. Itcan be obtained using special software or any web RSS generator like FeedBurner, or by using their XML code. Feed readers should be able to identify the generated feed as an RSS feed. These include:

- Feed for all: Runs on Windows operating systems. Available atwww.feedforall.net.

- Feed editor: Runs on MAC operating systems. Available atwww.extralabs.net.

- RSSeditor: Runs on Windows operating systems. Available atwww.rss-info.com.

- Feedity: An online tool. Available athttps://feedity.com/.
- Feedburner:An online tool from Googleprovides RSSfeeds forblogs likeWordPress, Bloggers and Tumblr. Available athttp://www.feedburner.com/.

The widely used hosting site www.archive.org was used for this study.It enables users to upload MP3 files, MP4files, and document files. It helps convert AVI files to MP4, it saves filesto a database for as long as possible, and it enables users export URLs of uploaded files to any webpage or blog.

\section{d) Publishing podcasts}

Publishing a podcast means delivering it to listeners as it is uploaded on the website or hosting site. The episode can be delivered in three ways: smartphones, personal computers, or SNSs (social network services). An RSS reader such as Coolsteache feed reader, iTunes, and RSS graffiti (for SNS) must be used. RSS reader applications can be uploaded from the Google Play Store or the Apple Store, and RSS graffiti can alsobe used through SNS as Facebook or twitter. Figure 2 shows how the episode is delivered to the learners.

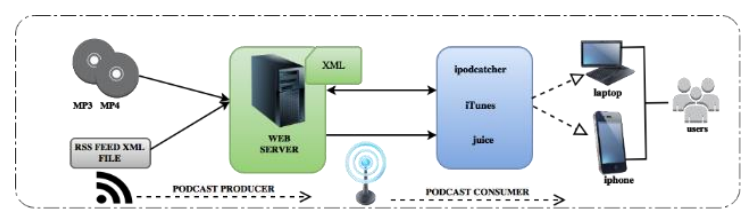

Fig. 2. How the episode is delivered to the learners

\section{CONTEXT-AwARE CATEGORIES}

"Context"can be defined as the information used to describe the situation of an entity. An entity is any relevant person, place, or object that can be relatedto the interaction between a user and an application. It can also include the user and the applications themselves [8]. Generally, context-aware technology provides information (location, social, time, physical context) about the learners to allowthe teacher tocontinuouslycommunicate with them. Itenablesthe student to describeeducational situations, communicate with the teacher, and to respond to class questions and discussions.Although there are many definitions of "context-awareness," its relationship to educationis less defined. It can be described as a technique to help communication between the teacher and the learner in the learning environment, in order to create elearning-specific instruction to connectreal world learning and reality environment. When content is sent to learners, the context-awarenessdetectstheir location and enables the instructor tobe aware of thelarge amount of information surroundingthem. It guides us through the information surrounding the students and adapts to their environment. [11][22]

\section{A. User Context}

\section{a) User Profile}

User profiles are important for determining the context of the learner for MPF.The instructor must identify the personality and identity of the learners, as MPFsendscontent to the learner but cannot identify him or her. MPF cannot answer the following questions: "who is the learner?", "What is his or her identity?", and "Howcan I communicate with him or her?"An ontology-based user profile model allows the user to have situation-aware MPF by controlling how many 
learners there are for specific categories of people in a given situation. Learner profiles must contain general information about learners, as they help determine the basic features of the learner and some details about the educational situation.

User profilescontain three details that help in recognizingthe learner's identity. They first identify unchangeable features like the name, the date of birth, and the address. Next, they contain a service profile, whichis related to the volume of the sound, its style, and the manner of the performance. The third identifier is calleda situationdependent profile, which contains the information related to the context such as the learner's locations. This information helps to identify individual learners, and makes it easier to communicate with them.Jellybean 4.3 is an application that helps the instructor identify the profile of the learner. It is a multi-user Google application, that can be used to add and manage user profiles and allows instructors to identify learners through their pictures.

\section{b) Location}

In MPF, the teacher will be aware of primary location but not of other locations, since the content is delivered electronically. "Location" involves information about the learner's surrounding environment.Glympseis an application that helps learners share their location using GPS. It does not require signing up for the service, but instead works anywhere the learners have GPS and a data connection. The instructor asksthe learners to share their locationssince it is very important for the learning situation.

\section{c) Location- based social network}

Some applications can be used to determine users' preferences. Friend's Latitude is an application from Google store that helps learners share their location directly during the learning process. It allows learners to share their location using GPS, and sends it through mobile and social media. Students can add some details about their places, whichpermitthe instructors to know their precise location, or simply if anyone will be nearby.

\section{d) Computing context}

With the use of smart devices in the transferring of the educational content to the learner through podcast technology, the teachers can facilitate the transfer process usinga variety of programs and applications. It now becomes necessary to understand the context of computing, as itis considered an essential part in the design of e-learning processes.The user interfaces for m-learning applications, which are based on podcast form, can be simple or complex according to the educational situation and the context of learner environment. Choosing colours, background, font size, button, and links is determined according to the context and the environment surrounding the learner. For example, using the application in sunny places is different from using it in the dark, since the purpose is providing an interface suitable for the user. [2][3]

Context computing is a process of transferring a computing application from desktop to mobile computing devices, which are adaptable to the environment. This is considered the third wave of computing, and it depends on a new paradigm of applications: sensor-based applications. In fact, using context computing createsapplications that are able to adapt automatically with changes in their physical surroundings, and helps strengthen the interaction between the learner and the mobile device.During the design of podcast applications on mobile phones, the location of the students during the learning process should be taken into account, and the application should be allowed to identify specific situations.[18]

Making a link between the MPF applications and learning programs should identify the location and other student details by means of a learning style, which uses multimedia (sound, animation, and video file). RFID (Radio-Frequency Identification) isa technology capable of providing students with some information about educational places they expect to visit [4]. RFID can be used to identify the learner using a RFID reader and a smart card that sends stored reader data wirelessly.The reader receives data from an identification card, which contains antenna that sends wireless waves that urge the card to send the storage data to the reader. These data are received and processed by the database. The context data cloud helps in learning more about learners, their profile, locations, and semantic locations.Friend's Latitude also providesthe instructor with more information about learners and their location.

\section{e) Physical context}

The student's physical context is the setting where your place is and where the learner is co-located. It is the state of the place where the learner exists. A number of questions can be posed about this, such as where the location is, what the weather conditions are like, what the temperature is, and what are the noiselevels.The learner's surrounding environment deeply affects the learning process, because learning is not only comprised of content and learner but also the environment.The temperature of the room and the equipped place generally affect the learning process. The surrounding environment, emotional status, and school performanceare all very influential.

Identifying the surrounding environment of the learner, while communicating and conveying the content, is very essential. The designer of the content should therefore provide application tools to help identify the learner's surrounding environment, and aid in receiving responses from 
the student during the learning process, especially for practical subjects where the learner is sent to special places such as the Internal Medicine department of a hospital. In these situations, the teacher also needs to make sure that the learner isin the right place, and can accomplish this throughGoogle's Beacons platform, which can find nearby beacons with real-time distance estimates. Beacons enable the user to locate any beacon, even without prior knowledge of its identifiers. Additionally, users can detect and decode beacons as well as calibrate their own.

\section{f) Sensors}

U-learning uses a large number of cooperative nodes with communication abilities, such as smart phones, sensors, network nodes, RFID, handheld terminals, and mobileIPs.Using RFIDtags, thesensors can detect the spatiotemporal conditions for the students. Wireless sensors networks (WSN) are the tool to collect important information everywhere, as they contain spatially autonomous sensorsthat detect physical conditions such as sound, temperature, motion vibration, or pressure, and convey these data to the main location. These wireless networks, which need little power, are able to acquire data quickly and communicate with other networks through a radio link. Data stored in the sensor nodes is compressed and sent to a base station "gateway," either directly or through other wireless sensor nodes.

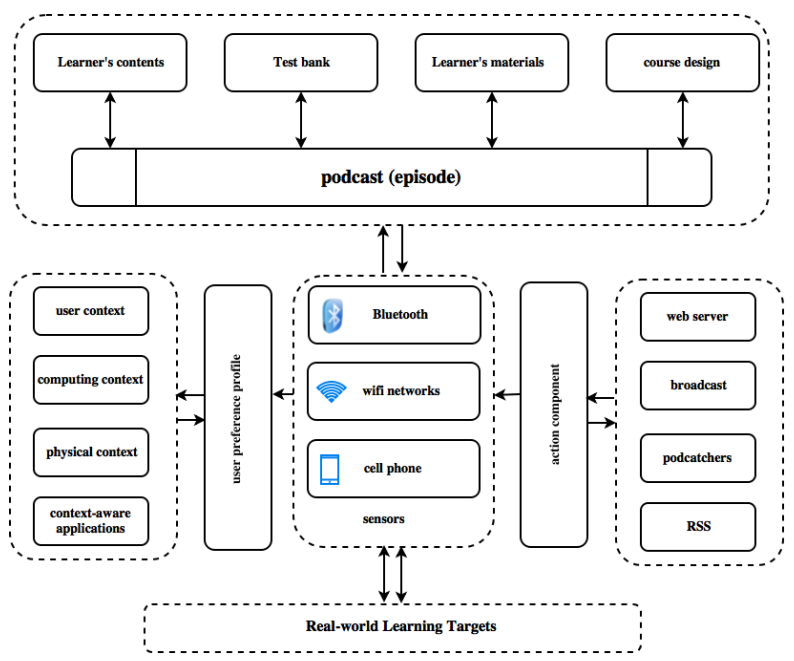

Fig. 3. The theoretical framework of context-aware technology in the podcast form (MPF)

\section{RESEARCH OBJECTIVES}

This study aims to:

- Present a framework for using context-aware technology in M-learning in the podcast form (MPF)
- Examine the effectiveness of using MPF engagement with context-aware technology in teaching and learning a multimedia course (IS 450).

\section{METHOD}

\section{a) Participants}

This study sought to investigate the effectiveness of using MPF with context-aware technology to learn multimedia IS 450 course. The perspective of learners were identified by collecting data from students $(n=42)$ enrolled in the IS 450 course. Participants completed an online survey (available at https://goo.gl/forms/U8vQBUj5pXo3ERzb2) after course completion.

\section{b) Instrument}

The survey instrument was developed through the following steps. First, the aim of the scale was described as obtainingfeedback on the effectiveness of using MPF with context-aware technology. A literature review to address the topic followed, and the areas of research were determined according to aforementioned aims. The instrument was then designed to have six components: Attitude towards Podcast $(A P)$, Intention to podcast (IP), Availability of applications (AA), Ease of podcast use (EP), Motivation to learn (ML) and Monitoring and Evaluation(ME). It consisted of (23) items distributed over six constructs, all of which used a five point Likert scale that ranged from 1 "strongly disagree," to 5 "strongly agree."Cronbach's $\alpha$ for the instrument was 0.928 and the revised consistency reliability was 0.82 , therefore the instrumentexceeded generally accepted validity and reliability standards for basic research. The correlation matrix between constructs were collected as shown in table:

\section{TABLE I. A CORRELATION MATRIX BETWEEN CONSTRUCTS}

\begin{tabular}{lllllll}
\hline Constructs & UA & CC & EL & CL & AU & IP \\
\hline AP & - & & & & & \\
IP & $.514^{*}$ & - & & & & \\
AA & $.760^{*}$ & $.558^{*}$ & - & & & \\
$\mathrm{EP}$ & $.819^{*}$ & $.444^{*}$ & $.574^{*}$ & - & & \\
ML & $.784^{*}$ & $.558^{*}$ & $.862^{*}$ & $.691^{*}$ & - & \\
ME & $.954^{*}$ & $.491^{*}$ & $.823^{*}$ & $.809^{*}$ & $.852^{*}$ & $1.00^{*}$ \\
\hline 2-tailed p values; ${ }^{*} \mathrm{p}<0.05,{ }^{* *} \mathrm{p}<0.01$ \\
Attitude towards Podcast (AP), Intention to podcast (IP), Availability of \\
applications (AA), Ease of podcast use (EP), Motivation to learn (ML), \\
Monitoring and Evaluation (ME).
\end{tabular}

\section{c) Procedures}

The study was conducted as a part of a college course, namely IS 450 multimedia course, and all study participants were enrolled in it. This course aimed to teach the students how to use multimedia in e-learning, and twelve lectures were createdin PowerPoint format and then converted to video 
podcasts. A weblog (http://is450.blogspot.com/) was set up to upload lecturers, and GoogleFeedBurner (https://feedburner.google.com/) was used to obtain RSS for the blog. The podcasts were made available online by uploading them on archive-web site (https://feedburner.google.com/) and linkingthem with the weblog. The RSS feed was sent to students via mail, and they were asked to download CoolesTeach Feed Reader to their mobile phones, theninput the RSS into the feed URL icon. They also received a video tutorial that explains how to do this. Context data cloud was used to follow students and connect with them. Lensoo Createapplication was used to respond to student inquiries.Figure 3 illustrates this process.

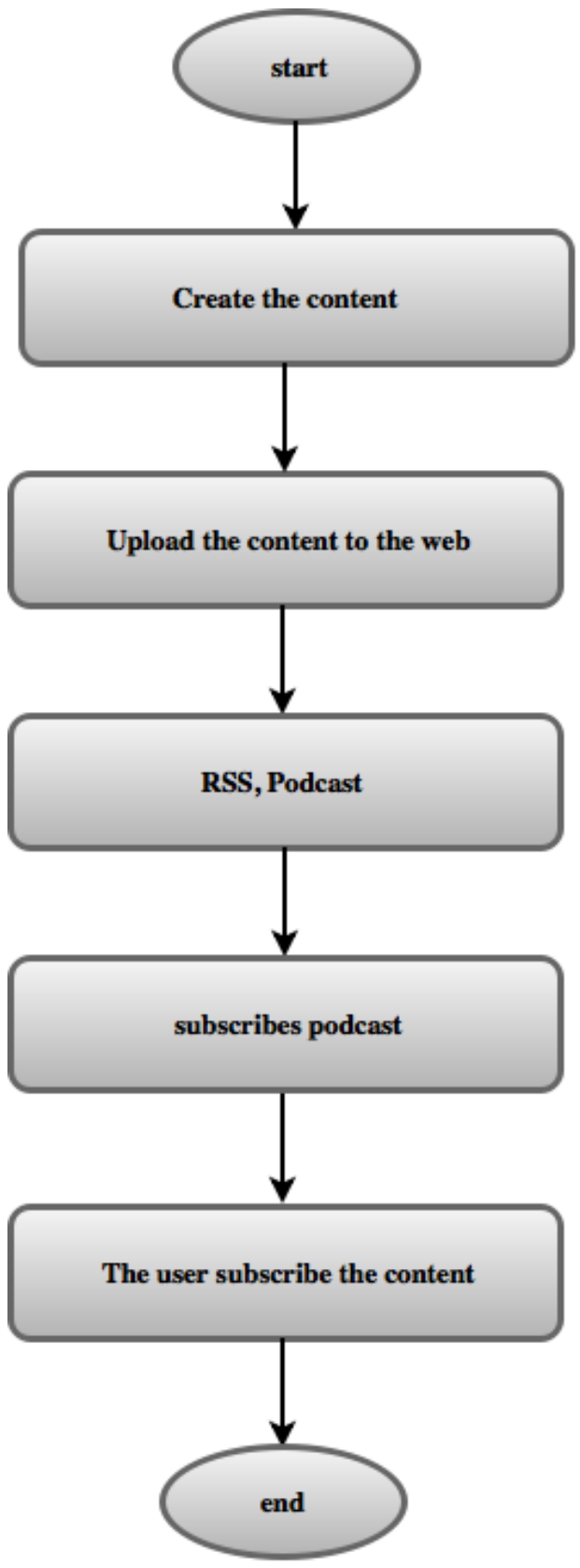

Fig. 4. Content delivered to users as podcast stack

\section{RESULTS}

a) Attitude towards Podcast (AP)

As Table 2 shows, students were asked to estimate their Attitude towards Podcast using context-aware applications in their studying for the IS450 course. Nearly $71.4 \%$ stated that they understood the ambiguity and subtle details when listening to the episodes $(\mathrm{M}=3.81, \mathrm{SD}=(1.087)$, and a chisquare analysis revealed that there is a significant difference between the actual and the expected opinion of the student $\left(\mathrm{X}^{2}\right.$ $(4,42)=13.95, \mathrm{p}<0.002)$ two-tails. $71.4 \%$ of the students also reported revising the lectures many times $(\mathrm{M}=3.29$, SD $=1.330),\left(\mathrm{X}^{2}(4,42)=10.85, \mathrm{p}<0.028\right)$. In general, students gave a positive impression towards podcast use. A comparison of students'Attitude towards Podcastis present in Figure 5, however, the percentage of student responses about this construct is quite high.

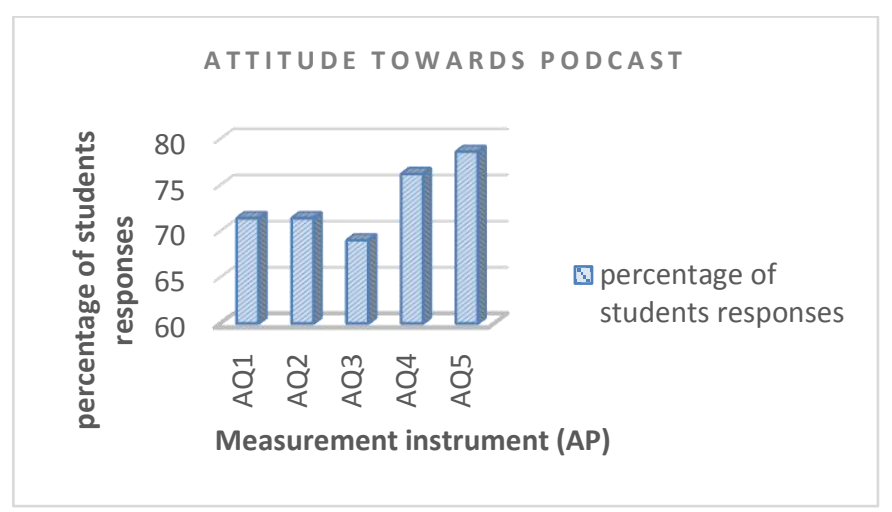

Fig. 5. Student's responses about Attitude toward Podcast

\section{b) Intention to podcast (IP)}

Students'responses about their Intention to podcast indicate that podcastsare an attractive format for them, as depicted in table 2. Nearly half of the students (47\%) reported that it provided good feedback. The results also indicate that there are significant differences between the students' actual and expected opinion $(\mathrm{M}=4.29, \mathrm{SD}=0.805),\left(\mathrm{X}^{2}(4,42)\right.$ $=36.81, \quad \mathrm{p}<0.000)$ two-tails.A comparison of students' Intention to podcast is presented in Figure 6.

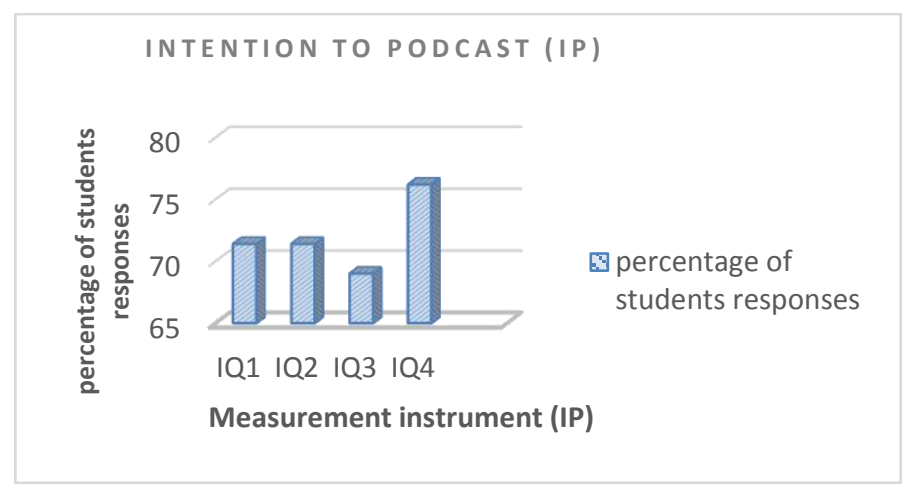

Fig. 6. Student's responses about Intention to podcast 


\section{c) Availability of Applications (AA)}

All applications used to publish the episodes were available to students, as table 1 demonstrates. $64.3 \%$ of the students reported that all podcast applications were available and easy to use $(\mathrm{M}=3.48, \mathrm{SD}=1.31),\left(\mathrm{X}^{2}(4,42)=13.47\right.$, $\mathrm{p}<0.000)$. They also reported that all context-aware applications were available and easy to use $(\mathrm{M}=3.24$, SD $=1.52),\left(\mathrm{X}^{2}(4,42)=5.61, \mathrm{p}<0.003\right)$. Students' responses about the Availability of Applications are shown in figure 7.

PERCENTAGE OF STUDENTS RESPONSES

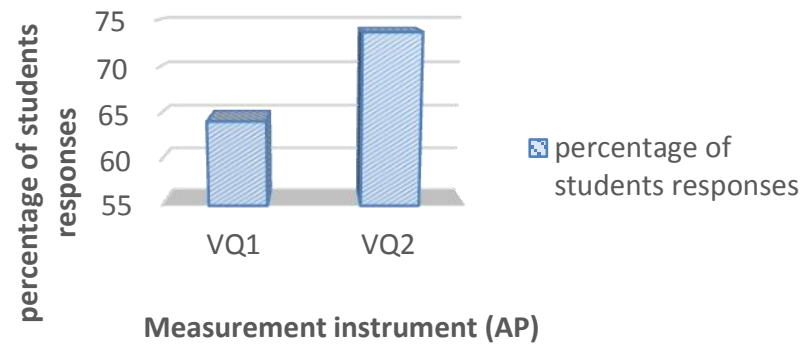

Fig. 7. Student's responses about Availability of Applications

\section{d) Motivation to Learn (ML)}

Students were asked if the use of podcasts in the learning process of the IS450 course motivated them to learn. More than half the students $(57.6 \%)$ reported that the use of podcasts increased their motivation toward learning $(\mathrm{M}=4.29$, $\mathrm{SD}=0.805),\left(\mathrm{X}^{2}(4,42)=18.23, \mathrm{p}<0.000\right)$. Students also reported that the use of podcasting supported cooperation between them $(\mathrm{M}=3.57, \mathrm{SD}=1.72),\left(\mathrm{X}^{2}(4,42)=21.57\right.$, $\mathrm{p}<0.007)$. These resultsshow that MPF motivates both individual and collective learning. Students' responses about Motivation to Learn are shown in figure 8.

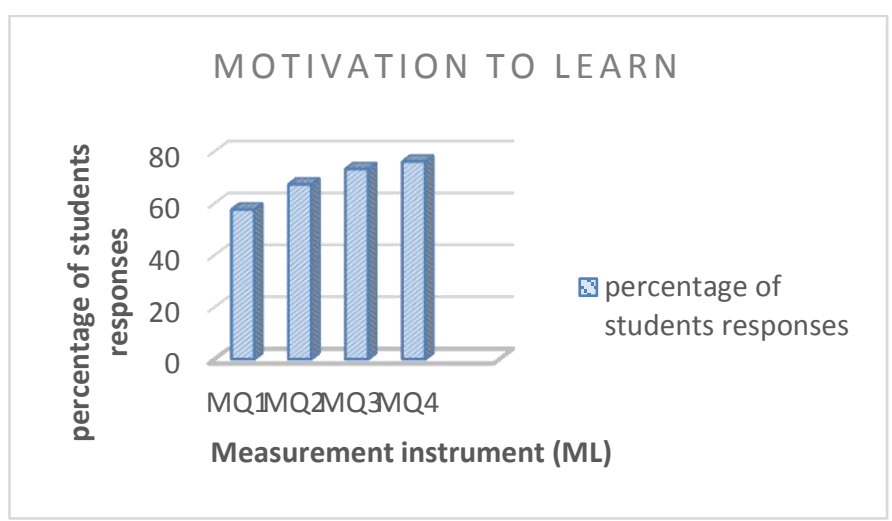

Fig. 8. Student's responses about Motivation to Learn

\section{e) Ease of Podcast use(EP)}

Students reported that the episodes were clear, simple, and appropriate to their levels $(\mathrm{M}=3.57, \mathrm{SD}=1.15), \quad\left(\mathrm{X}^{2}(4\right.$, $42)=12.28, \mathrm{p}<0.000) .42 .6 \%$ of respondents indicated that the episodeswere flexible and integrated. Students also had the opinion that the use of podcasts through their devices was an easy and well-pacedway to learn. Students' responses about Ease of Podcast use are shown in figure 9.

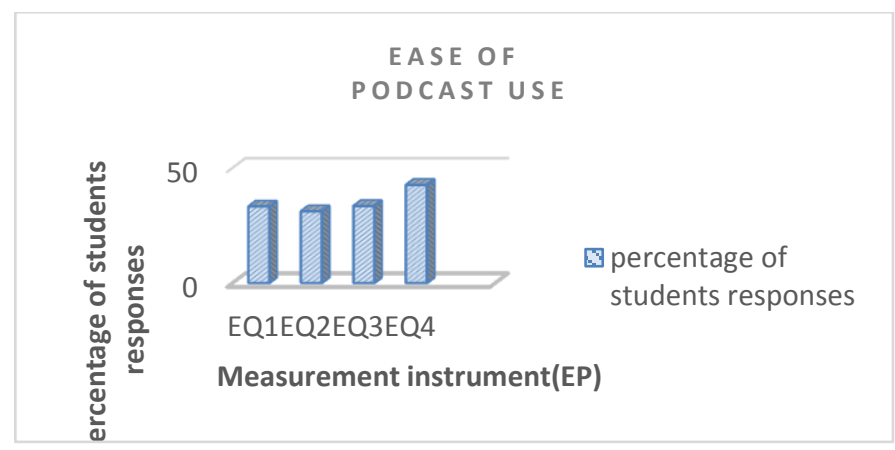

Fig. 9. Student's responses about Ease of Podcast use

\section{f) Monitoring and Evaluation (ME)}

The main purpose of using context-aware applications is following up with students and communicating with them. Students were asked about Monitoring and Evaluation, and $65.1 \%$ of them responded that the teacher's follow up made them more careful $(\mathrm{M}=3.67, \mathrm{SD}=1.20),\left(\mathrm{X}^{2}(4,42)=18.23\right.$, $\mathrm{p}<0.002)$. Additionally, a sizable group $(71.3 \%)$ reported that the fact that the teacher care to know about their surroundings made them more considerate $(M=3.36, S D=1.34),\left(X^{2}(4,42)\right.$ $=10.61, \mathrm{p}<0.034)$. In general, student had a positive attitude toward the teacher's follow up. Students' responses about Monitoring and Evaluation are shown in figure 9.

\section{MONITORING AND EVALUATION}

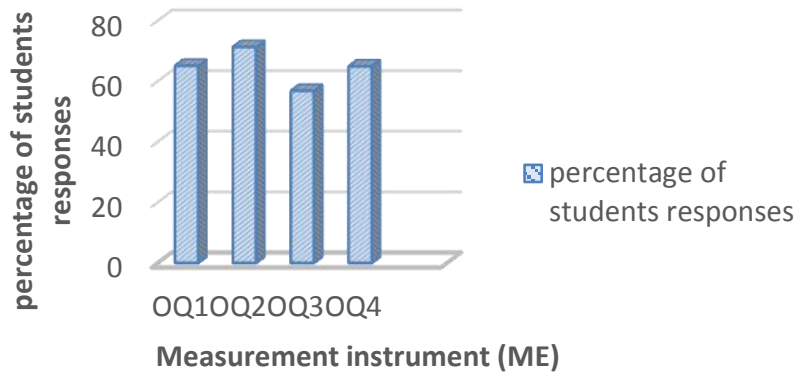

Fig. 10. Student's responses about Monitoring and Evaluation 
TABLE II. MEANS, STANDARD DEVIATION, CHI SQUARED AND CONSTRUCT RELIABILITY

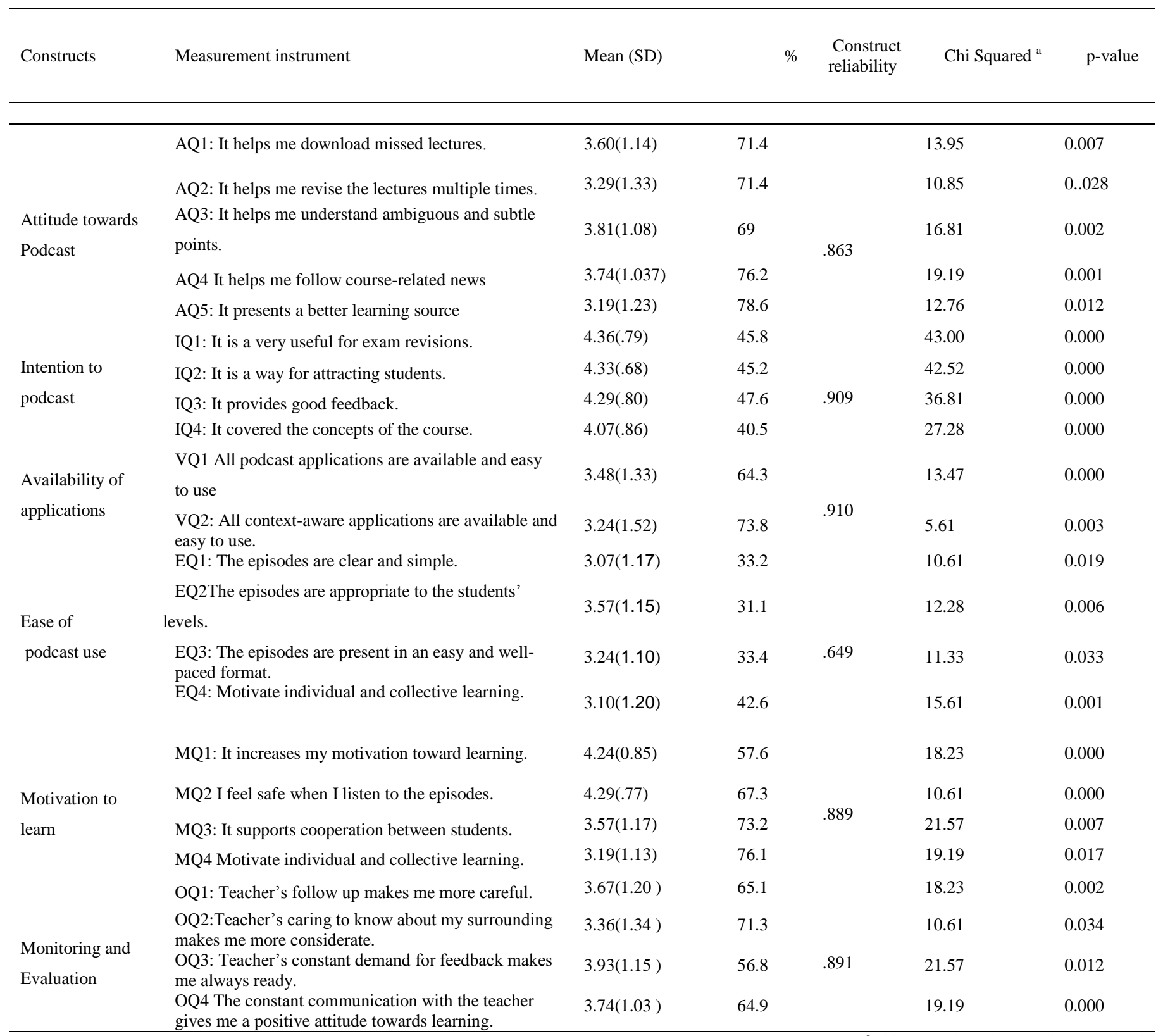

\section{CONCLUSION}

MPF is m-learning that depends on the podcast form to send educational content uploaded by the instructor to the students, who receive it through podcatchers on PADS, iPhones, Android devices, laptops, and PCs. Using podcast technology by itself doesn't enable instructors to be aware of the learners'identity, current status, or their surrounding environment during the learning process, which reflects poorly on the completeness of the educational process.

Due to the importance of completing the learning process properly, the environment surrounding the learners (the place, the time, the location, and the status) should be defined.This study presents a theoretical framework of using "context- awareness" in M-learning in the podcast form (MPF). It takes into account the clarity and the simplicity in the presentation of the framework, in order to help MPF research and design. Additionally, it presents a context-aware calendar application built according to an out-of-context framework.

This research presents a case study of a computer department multimedia course (IS 450) at Qassim University. Course lectures were presented through podcast episodes, and students were followed up via context-aware applications. We asked the students to complete a questionnaire, after completing the course, to measure the effectiveness of this learning method. The results indicate that students have a positive attitude toward using (MPF) for coursework, and confirmed that podcasting and context-aware technology had a 
significant impact on learning in the multimedia IS 450 course.

\section{REFERENCES}

[1] Aparici, M., Bacao , F., \& Oliveira , T. (2016). An e-Learning Theoretical Framework. Educational Technology \& Society, 19 (1), 292-307.

[2] Baran, E. (2014). A Review of Research on Mobile Learning in Teacher Education A Review of Research on Mobile Learning in Teacher Education.A Review of Research on Mobile Learning in Teacher Education.A Review of Research on Mobile Learning in Teacher Education .A Review of R. Educational Technology \& Society, 17(4), $17-32$.

[3] Bogdanovic, Z., Barac, D., Jovanic, B., Popovic, S., \& Radenkovic, B. (2015). Evaluation of mobile assessment in a learning management system. British Journal of Educational Technology, 45(2), 231-244.

[4] Chen, C. C., \& uang, T. C. (2012). Learning in a u-Museum: Developing a context-aware ubiquitous learning environment. Computers \& Education, Elsevier, 59, 873-883.

[5] Chia-Chen, C., \& Tien-Chi., H. (2012., Nov). Learning in a u-Museum: Developing a Context-Aware Ubiquitous Learning Environment. Computers \& Education, v59 n3, 873-883.

[6] Chih Lai, H., Yen Chang, C., Shiane Li, W., Lin Fan, Y., \& Tien Wu, Y. (2013). The implementation of mobile learning in outdoor education: Application of QR codes. British Journal of Educational Technology, 44(2), E57-E62.

[7] Crompton, H. ( 2015). Understanding Angle and Angle Measure: A Design-Based Research Study Using Context Aware Ubiquitous Learning. International Journal for Technology in Mathematics Education, v22 n1(1744-2710.), p19-30.

[8] Dey, A. K. \& Abowd, G. D. (2000). Towards a Better Understanding of Context and Context-Awareness, CHI 2000 Workshop on the What, Who, Where, When, and How of Context-Awareness.

[9] Evans, C. (2008). The effectiveness of m-learning in the form of podcast revision lectures in higher education. Computers \& Education, Elsevier, $50,491-498$.

[10] H. Kay, R. (2012). Exploring the use of video podcasts in education: A comprehensive review of the literature. Computers in Human Behavior, 820-831.
[11] Huang, Y. M., \& Chiu, P.-S. (2015). The effectiveness of a meaningful learning-based evaluation model for context-aware mobile learning. British Journal of Educational Technology, 46(2), 437-447.

[12] Ju-Ling, S., Hui-Chun, C., Gwo-Jen, H., \& Kinshuk. (2011, May). An Investigation of Attitudes of Students and Teachers about Participating in a Context-Aware Ubiquitous Learning Activity. British Journal of Educational Technology, v42 n3(0007-1013.), 373-394.

[13] Li, M., Ogata, H., Hou, B., Uosaki, N., \& Mouri, K. (2013). Contextaware and Personalization Method in Ubiquitous Learning Log System. Educational Technology \& Society, 16(3), 362-373.

[14] Mandula, K., Rao Meda, S., Kumar Jain, D., \& Kambham, R. (July 2011). Implementation of Ubiquitous Learning System Using Sensor Technologies. Technology for Education (T4E), 2011 IEEE International Conference (pp. 142 - 148). Chennai, Tamil Nadu: IEEE.

[15] Mohammad A. Amasha and Salem Alkhalaf (2016)Using RSS 2.00 as a Model for u-Learning to Develop e-Training in Saudi Arabia|Using RSS 2.00 as a Model for u-Learning to Develop e-Training in Saudi Arabia, IJIET 2016 Vol.6(7): 516-521 ISSN: 2010-3689.

[16] Nguyen, L., Barton, S. M., \& Nguyen, L. T. (2015). iPads in higher education-Hype and hope. British Journal of Educational Technology, 46(1), 190-203.

[17] Ouwehand, K., Gog , T. v., \& Paas , F. (2015). Designing Effective Video-Based Modeling Examples Using Gaze and Gesture Cues. Educational Technology \& Society, 18 (4), 78-88.

[18] P.-S, T., C.-C, T., \& G.-J, H. (2012, Jun). Developing a Survey for Assessing Preferences in Constructivist Context-Aware Ubiquitous Learning Environments. Journal of Computer Assisted Learning, v28 n3(0266-4909.), 250-264.

[19] S. Fallahkhair, L. Pemberton, \& R. Griffiths. (2007). Development of a cross-platform ubiquitous language learning service via mobile phone and interactive television. Journal of Computer Assisted Learning, 23, 312-325.

[20] S, S. N., \& Göktas, Ö. (2014). Preservice teachers' perceptions about using mobile phones and laptops in education as mobile learning tools. British Journal of Educational Technology, 45(4), 606-618.

[21] T.-Y., L. (2009, Dec). A Context-Aware Ubiquitous Learning Environment for Language Listening and Speaking. Journal of Computer Assisted Learning, v25 n6(0266-4909), 515-527.

[22] You, J. W. (2015). Examining the Effect of Academic Procrastination on Achievement Using LMS Data in e-Learning. Educational Technology \& Society, 18 (3), 64-74. 